Решетникова И.Д. ${ }^{1,2}$, Агафонова Е.В. ${ }^{1,3}$, Тюрин Ю.А. ${ }^{1,3}$, Куликов С.Н. ${ }^{1,2}$, Гилязутдинова Г.Ф. ${ }^{1}$, Лопушов Д.В. ${ }^{3,4}$, Шайхразиева Н.Д. ${ }^{4}$, Исаева Г.Ш. ${ }^{1,3}$, Зиатдинов В.Б. ${ }^{1}$

1 ФБУН «Казанский научно-исследовательский институт эпидемиологии и микробиологии» Роспотребнадзора, Казань, 420015, г. Казань, ул. Большая Красная, 67, Россия

${ }^{2}$ ФГАОУ ВО «Казанский (Приволжский) федеральный университет, г. Казань, ул. Кремлёвская, 18, Россия

3 ФГБОУ ВО «Казанский государственный медицинский университет», г. Казань, 420012, г. Казань, ул. Бутлерова, 49, Россия

${ }^{4}$ Казанская государственная медицинская академия - филиал ГБОУ ДПО РМАНПО Минздрава России, 420012, г. Казань, ул. Муштари, 11, Россия

\title{
Опыт изучения коллективного и персонального иммунитета к вирусу SARS-CoV-2 y медицинских работников
}

Резюме. Проведено выборочное изучение серопревалентности к вирусу SARS-CoV-2 среди 348 медицинских работников (MP) 10 медицинских организаций г. Казани: многопрофильных стационаров, которые были перепрофилированы для оказания медицинской помощи больным коронавирусной инфекцией (МС 1-7), станции скорой медицинской помощи (СМП1), медицинской организации, осуществляющей амбулаторнополиклиническую деятельность (АПП1) и специализированной поликлиники (СП1). Для определения IgG использовался твердофазный ИФА. Доля МР различных медицинских организаций г. Казани серопревалентность по IgG антителам к вирусу SARS-CoV-2 составляет 16,4%. Широкое варьирование значения серопревалентности групп МР различных медицинских организаций (3.3-30.8\%) может свидетельствовать о разном уровне эффективности противоэпидемических мероприятий в данных учреждения. Сравнительно низкая доля положительных анализов на антитела к вирусу SARS-CoV-2 у MP специализированной поликлиники (6.1\%) может свидетельствовать об эффекте весеннего карантина. В целом по группе МР с серопозитивными результатами отмечается превалирование доли с очень высоким коэффициентом позитивности (49,1\%), что характеризует высокую напряжённость иммунного ответа. Отмечена корреляция между величиной серопревалентности у МР медицинской организации с долей положительных сывороток, показавших большие коэффициенты позитивности. 
Ключевые слова: серопревалентность по IgG антителам к вирусу SARS-CoV-2, новая коронавирусная инфекция COVID-19, медицинские работники

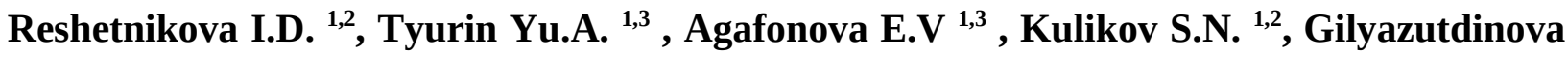
G.F. ${ }^{1}$, Lopushov D.V. ${ }^{3,4}$, Shaykhrazieva N.D. ${ }^{4}$, Isaeva G.Sh. ${ }^{1,3}$, Ziatdinov V.B. ${ }^{1}$

\section{${ }^{1}$ Kazan Scientific Research Institute of Epidemiology and Microbiology, Kazan, Russia; \\ ${ }^{2}$ Kazan Federal University, Kazan, Russia; \\ 3 Kazan State Medical University of the Ministry of Health of Russia, Kazan, Russia; \\ ${ }^{4}$ Kazan State Medical Academy of the Ministry of Health of Russia, Kazan, Russia. \\ Experience in studying collective and personal immunity to the SARS-CoV-2 virus in medical workers}

Abstract. A selective study of seroprevalence to the SARS-CoV-2 virus was carried out among 348 medical workers (MR) of 10 medical organizations in Kazan: multidisciplinary hospitals that were redesigned to provide medical care to patients with coronavirus infection (H1-7), ambulance stations (AS1), a medical organization carrying out outpatient polyclinic activities (P1) and a specialized polyclinic (SP1). A solid-phase ELISA was used for the determination of IgG. The share of MR of various medical organizations in Kazan seroprevalence for IgG antibodies to SARS-CoV-2 virus is $16.4 \%$. The wide variation in the seroprevalence value of MR groups of different medical organizations (3.3-30.8\%) may indicate a different level of effectiveness of anti-epidemic measures in these institutions. The relatively low proportion of positive tests for antibodies to the SARS-CoV-2 virus in the MR of a specialized polyclinic (6.1\%) may indicate the effect of spring quarantine. In general, in the group of MR with seropositive results, the prevalence of the proportion with a very high positivity rate $(49.1 \%)$ is noted, which characterizes the high intensity of the immune response. There was a correlation between the value of seroprevalence in MR of a medical organization with the proportion of positive sera that showed hig

Key words: seroprevalence for IgG antibodies to SARS-CoV-2 virus, novel coronavirus infection COVID-19, healthcare workersh coefficients of positivity.

Conflict of interest: The authors declare no conflict of interest.

Corresponding author: Reshetnikova Irina, e-mail:reshira@mail.ru.

Решетникова Ирина Дмитриевна, к.м.н., доцент, ФБУН «Казанский научноисследовательский институт эпидемиологии и микробиологии» Роспотребнадзора, заместитель директора по научной работе, 420015. Россия, г. Казань, ул. Б. Красная, 67; 
тел. (843) 236-67-21; факс . (843) 2366741. Доцент кафедры фундаментальных основ клинической медицины ИФМиБ ФГАОУ ВО «Казанский (Приволжский) федеральный университет, г.Казань, Россия, 420008, Россия, г. Казань, ул. Кремлевская. 18; ORCID: 0000-0002-3584-6861 e-mail: reshira@mail.ru

Reshetnikova I.D., MD, PhD, Deputy Head of Kazan Scientific Research Institute of Epidemiology and Microbiology, 67, Bolshaya Krasnaya str., Kazan, Russia, 420015. Senior lecturer of Kazan Federal University, Kazan, Russia

Тюрин Юрий Александрович, к.м.н., заведующий лабораторией иммунологии и разработки аллергенов, ведущий научный сотрудник, ФБУН «Казанский научноисследовательский институт эпидемиологии и микробиологии» Роспотребнадзора; ассистент кафедры биохимии и клинической лабораторной диагностики ФГАОУ ВО «Казанский (Приволжский) федеральный университет. ORCID: 0000-0002-2536-3604 tyurin.yurii@yandex.ru

Tyurin Yu.A., MD, PhD, head of immunology laboratory of Kazan Scientific Research Institute of Epidemiology and Microbiology, Assistant at the Department of Biochemistry and Clinical Laboratory Diagnostics Kazan State Medical University of the Ministry of Health of Russia

Агафонова Елена Валентиновна, к.м.н., врач клинической лабораторной диагностики консультативно-диагностической поликлиники инфекционно- аллергических заболеваний ФБУН «Казанский научно-исследовательский институт эпидемиологии и микробиологии» Роспотребнадзора, ассистент кафедры пропедевтики детских болезней ФГБОУ ВО «Казанский государственный медицинский университет». ORCID: 0000-0002-4411-8786; agafono@mail.ru

Agafonova E.V., MD, PhD, laboratory diagnostics doctor Kazan Scientific Research Institute of Epidemiology and Microbiology, assistant Department of Propedeutics of Childhood Diseases Kazan State Medical University of the Ministry of Health of Russia

Куликов Сергей Николаевич, к.б.н., ведущий научный сотрудник лаборатории иммунологии и разработки аллергенов, ФБУН «Казанский научно-исследовательский институт эпидемиологии и микробиологии» Роспотребнадзора. ORCID : 0000-0001-62602363, kuliks@yandex.ru

Kulikov S.N. PhD, leading researchers at immunology laboratory of Kazan Scientific Research Institute of Epidemiology and Microbiology

Гилязутдинова Гульнара Фанилевна, врач эпидемиолог консультативнодиагностической поликлиники инфекционно- аллергических заболеваний ФБУН 
«Казанский научно-исследовательский институт эпидемиологии и микробиологии» Роспотребнадзора. ORCID: 0000-0001-9159-2205; florimel17@yandex.ru

Gilyazutdinova G.F., MD, epidemiologist of Kazan Scientific Research Institute of Epidemiology and Microbiology

Лопушов Дмитрий Владимирович, к.м.н., доцент кафедры профилактической медицины и экологии человека ФГБОУ ВО «Казанский государственный медицинский университет»; доцент кафедры эпидемиологии и дезинфектологии Казанская государственная медицинская академия - филиал ГБОУ ДПО РМАНПО Минздрава России. ORCID: 0000-0001-8896-969X, doctor225@mail.ru

Lopushov D.V., MD, PhD, Associate Professor at the Department of Preventive Medicine and Human Ecology Kazan State Medical University of the Ministry of Health of Russia; Associate Professor at the Department of Epidemiology and Disinfectology of Kazan State Medical Academy of the Ministry of Health of Russia

Шайхразиева Наталья Дмитриевна, к.м.н., доцент кафедры эпидемиологии и дезинфектологии Казанская государственная медицинская академия - филиал ГБОУ ДПО РМАНПО Минздрава России. ORCID: 0000-0002-2241-3100 ; epid-gkb7@mail.ru

Shaykhrazieva N.D., MD, PhD, Associate Professor at the Department of Epidemiology and Disinfectology of Kazan State Medical Academy of the Ministry of Health of Russia

Исаева Гузель Шавхатовна, д.м.н., профессор, заместитель директора по инновационному развитию ФБУН «Казанский научно-исследовательский институт эпидемиологии и микробиологии» Роспотребнадзора, заведующий кафедрой микробиологии имени академика В.М. Аристовского ФГБОУ ВО «Казанский государственный медицинский университет» Министерства здравоохранения РФ. ORCID:0000-0002-1462-8734 e-mail: kniem@mail.ru;

Isaeva G.Sh., MD, PhD, professor , Deputy Director for Innovative Development of Kazan Scientific Research Institute of Epidemiology and Microbiology; Head of the Department of Microbiology named after Academician V.M. Aristovsky of Kazan State Medical University of the Ministry of Health of Russia

Зиатдинов Васил Билалович, д.м.н. директор ФБУН «Казанский научноисследовательский институт эпидемиологии и микробиологии» Роспотребнадзора. ORCID: 0000-0001-8029-6515e-mail: kniem@mail.ru

Ziatdinov V.B. MD, PhD, professor, head of Kazan Scientific Research Institute of Epidemiology and Microbiology

По мере распространения пандемии SARS-CoV-2 одними из первых стали появляться сообщения о случаях инфицирования вирусом медицинских работников (МР), 
являющихся категорией потенциального (повышенного) риска заражения [1,2,3,4,5]. По данным китайских учёных случаи SARS-CoV-2 у MP внесли существенный вклад в распространение заболеваемости - в 422 медицинских учреждениях с начала эпидемии по состоянию на 11 февраля 2020 г выявлено 1716 лабораторно подтверждённых случаев среди МР [6].

По результатам анализа распространения SARS-CoV-2 в мире и Российской Федерации, проведенного Роспотребнадзором, Российским научно-исследовательским противочумным институтом «Микроб», и Российской медицинской академией непрерывного профессионального образования, МР, наряду с детьми, лицами, страдающими хроническими заболеваниями сердечно-сосудистой и эндокринной систем, лицами старше 65 лет, являются наиболее уязвимыми контингентами в отношении SARSCoV-2. Отдельно подчёркивается, что среди инфицированных отмечается высокая доля MP - 7.6\%, а 7.7\% от всех заболевших заражаются в медицинских организациях. Данное наблюдение указывает на важность обеспечения противоэпидемического режима и выполнения требований биологической безопасности в период пандемии SARS-CoV-2 как в специализированных медицинских организациях, так и в клиниках общего профиля [7,8,9] . Причины отнесения МР к наиболее уязвимой категории очевидны и связаны, с одной стороны, с повышенной вероятностью контакта с зараженными или «лицами из групп риска» в силу профессиональной деятельности, и циркуляции патогена в медицинских организациях, с другой стороны, с возможностью передачи инфекции при отсутствии симптомов заболевания или в продромальном периоде, а также наличием в недостаточном количестве или неправильном использовании средств индивидуальной защиты и несоблюдением мер индивидуальной защиты.

Применение серологических методов для изучения распространения SARS-CoV-2 среди МР продемонстрировано в немногочисленных исследованиях, данные которых зачастую противоречивы. Так, по оценке исследователей из Китая при обследовании 19555 MP специфические IgG к SARS-Cov-2 выявлялись только у 4\% [10.]. По данным авторов из Германии антитела к SARS-CoV-2 в группе медицинского персонала варьировала в зависимости от степени риска заражения: в группе умеренного риска серопревалентность составила 1,2\%, в группой высокого риска 5,4\% [11, 12]. По результатам исследований, проведенных в Испании выявляемость антител к SARS-CoV-2 составила 9,8\%, причём у 40\% диагноз новой коронавирусной инфекции установить не удалось [13].

Показана существенная роль «носителей» SARS-CoV-2 в распространении инфекции, активном вовлечении асимптоматических форм новой коронавирусной 
инфекции в эпидемический процесс. [14] В Италии среди медицинских работников крупного онкологического центра бессимптомное течение выявлено у 9.4\% медработников, причем у 31.8\% из них были выявлены PHK SARS-CoV-2 в респираторных мазках, что свидетельствовало об активном инфекционном процессе [15]. В США у сотрудников и пациентов амбулаторного диализного центра через 21 день после общения с зараженным SARS-CoV-2 выявлено наличие специфических IgM и/или IgG у 23\% пациентов и 44\% сотрудников, причём без признаков клинического проявления [16]. А по результатам расследования вспышки SARS-CoV-2 в реабилитационном центре в штате Вашингтон (США) показано, что доля бессимптомного течения составила 56\% (27 человек из 48 с положительным результатом ПЦР). В дальнейшем оказалось, что у 24 из 27 таких пациентов развилась симптоматика (в 50\% случаев) и только 3 человека (6\%) остались истинными «носителями» [17].

Об уровне серопревалентности среди работников здравоохранения в Российской Федерации можно судить по результатам проведения масштабного проекта Роспотребнадзора по изучению популяционного иммунитета к вирусу SARS-CoV-2 - так в Санкт-Петербурге данный показатель составил 27,1\% [18] , а в Ленинградской области 18,1\% [19]. Серологические исследования отдельных коллективов МР направлены на выявление частоты распространения инфекции, особенно бессимптомных форм болезни в организациях здравоохранения, с целью своевременной изоляции и лечения заразившихся MP, снижения риска внутрибольничного инфицирования, а также анализа популяционного иммунитета среди контингентов с высоким риском заражения.

Целью исследования являлось определение серопревалентности по антителам к SARS-CoV-2 среди MP г. Казани.

\section{Материалы и методы}

Материалом служили сыворотки крови 348 МР 10 медицинских организаций г.Казани. Первая группа организаций (предполагаемый «высокий риск») включала в себя 7 многопрофильных стационаров (МС) г. Казани, которые были перепрофилированы для оказания медицинской помощи больным коронавирусной инфекцией, вторая группа (предполагаемый «умеренный риск») - станцию скорой помощи (СМП) и медицинскую организацию, оказывающую амбулаторно-поликлиническую (АПП) помощь, третья группа (предполагаемый «низкий риск»)- специализированную поликлинику (СП) (Табл. 1).

Отбор медицинских работников для исследования проводился методом случайной выборки [20]. После подписания информированного согласия были собраны клинические, анамнестические данные и эпидемиологический анамнез в отношении SARS-CoV-2 c 
помощью специально разработанной анкеты с указанием симптомов ОРВИ в течение последних 14 дней (повышение температуры тела, сухой кашель с небольшим количеством мокроты, боли в мышцах, утомляемость, одышка ощущение заложенности в груди), перенесённых за последние 3 месяца фарингита/трахеита, бронхита и внебольничной пневмонии, пребывание в регионах неблагополучных по SARS-CoV-2, принадлежность к группе риска (наличие сопутствующих заболеваний: сердечнососудистых, хронических неспецифических болезней легких, сахарного диабета и др.), отдельным пунктом выделялись контакты с больными SARS-CoV-2, результаты исследования мазков из носоглотки/ротоглотки на наличие SARS-CoV-2.

Для определения IgG использовался двухстадийный непрямой вариант твердофазного ИФА тест системы «SARS-CoV-2-Ig G-ИФА-БЕСТ». Для расчётов использовался коэффициент позитивности (КП), который представляет из себя соотношение значения оптической плотности опытного образца (ОПобр) к значению оптической плотности отрицательного контрольного образца (ОП К-)+0.2. Результат считался отрицательным при КП <0.8, положительными при КП $\geq 1.1$ и пограничными при $0.8<\mathrm{K \Pi}<1.1$.

Исследование одобрено локальным этическим комитетом ФБУН КНИИЭМ Роспотребнадзора.

Статистическая обработка результатов проводилась с применением программного обеспечения MS Exel. Для оценки достоверности различий применяли критерий Стъюдента (t-критерий) для независимых выборок. Считали различия достоверными при $\mathrm{p}<5 \%$. Для получения коэффициента корреляции использовали метод ранговой корреляции Спирмена, при $\mathrm{R}>0.66$ принимали наличие положительной корреляции.

\section{Результаты и их обсуждение}

Все МР отметили на момент исследования и за последние 3 месяца отсутствие симптомов фарингита, трахеита, бронхита, внебольничной пневмонии, в течении последних 14 дней отсутствие симптомов ОРВИ, отрицательные результаты исследований мазков из носоглотки/ротоглотки на наличие SARS-CoV-2.

В целом, для MP различных медицинских организаций г.Казани, серопревалентность по IgG к вирусу SARS-CoV-2 варьировала в пределах 3.3-30.8\% и, в среднем, составила 16.4 \% (табл. 2). Данные нашего исследования сопоставимы с результатами широкомасштабного проекта Роспотребнадзора по оценке популяционного иммунитета к SARS-CoV-2 в Российской Федерации, показавших уровень серопозитивности у работников здравоохранения в Санкт- Петербурге (27.1\%) и в 
Ленинградской области (17.1\%) [18,19.]. До введения вакцинации выявление IgG к возбудителю SARS-CoV-2 свидетельствует, что человек переболел коронавирусной инфекцией $[21,22,23,24]$. Как было отмечено ранее, описано два варианта асимптоматического течения новой коронавирусной инфекции. Во-первых, «носительство» вируса, когда на протяжении всего инфекционного периода у инфицированного человека отсутствуют клинические признаки и изменения легочной ткани на компьютерной томографии, типичные для SARS-CoV-2. Bo-вторых, «предсимптоматическое носительство» (пациенты в инкубационном периоде заболевания) с наличием PHK SARS-CoV-2 в респираторных мазках и развитием с течением времени клинических проявлений. [14, 25, 26, 27, 28, 29]. Необходимо отметить сложности выявления «носителей» SARS-CoV-2, так как такие контингенты, как правило выявляются лишь при случайных обследованиях. Однако, данная категория инфицированных лиц представляет эпидемиологическую опасность и усложняет эпидемиологический надзор за инфекцией. Их активное выявление, в том числе при изучении распространенности указанной клинической формы заболевания среди МР и населения в целом, а также своевременная изоляция и лечение «носителей», по мнению исследователей, могут стать ключевыми мерами, ведущими к сдерживанию распространения инфекции [30,31,32,33]. Таким образом, формирование серопревалентности по антителам к SARS-CoV-2 среди MP происходит за счёт лиц как с бессимптомными формами инфекции, так и, возможно, за счёт контингентов, находящихся на предсимптомной стадии заболевания, что требует проведения серомониторинга за серопозитивными лицами и сероэпидемиологического анализа в отношении дифференциальной диагностики бессимптомного и предсимптомного носительства.

Важным показателем, характеризующим коллективный иммунитет в группе риска МР, является показатель серопревалентности по отдельным медицинским организациям. В первой группе медицинских организаций отмечено широкое варьирование значения серопревалентности групп МР, которая в среднем составляла 16.7\% (Табл. 2). Среди них есть две организации, в которых величины серопревалентности значительно превышают средний показатель: МС6 (30.8\%) и MC7 (30.0\%) и две организации, в которых величины серопревалентности заметно ниже среднего показателя - MC1 (5.0 \%) и MC3 (3.3\%). Такие различия показателя серопревалентности в группе медицинских стационаров, перепрофилированных для лечения инфекции SARS-CoV-2, могут объясняться различным уровнем эффективности противоэпидемических мер в каждой конкретной медицинской организации, включающих приспособленные помещения, оснащение всем необходимым оборудованием и средствами индивидуальной защиты, грамотными и ответственными 
действиями медицинского персонала и администрации, должной организацией противоэпидемических мероприятий

Во второй группе серопревалентность регистрировалась в среднем на уровне $23.3 \%$. Серопревалентность у МР СМП составила 27,5\%, то есть находилась в области близкой к самым высоким уровням этого показателя для самых неблагополучных медицинских организаций из первой группы. Тогда как у МР АМП величина серопревалентности (15\%) была сопоставима со средним значением для всех исследуемых медицинских организаций.

Сравнительно низкая доля положительных анализов на антитела к вирусу SARSCoV-2 у работников СП (6.1\%) из третьей группы может свидетельствовать об эффекте весеннего карантина, в период которого данная медицинская организация, в отличие от всех остальных, переходила на дистанционный режим работы.

Для оценки формирования популяционного иммунитета у МР особое значение имеет сопоставление серопозитивности результата анализа сывороток с наличием или отсутствием у исследуемых лиц контакта с больными SARS-CoV-2, в соответствии с чем все МР были разделены на «контактные» и «не контактные». Среди всех МР к группе «контактных» относилось 77.8\% МР, то есть большинство (Табл. 2). Однако, для МР медицинских организаций первой группы наличие или отсутствие контакта с больными SARS-CoV-2 не влияло на вероятность наличия у них специфических IgG - доля положительных результатов теста была сопоставима в обоих случаях. Значительно отличались доли положительных результатов среди «контактных» и «неконтактных» в остальных трёх учреждениях - СМП, АПП и СП. В СМП все имеющие антитела к вирусу МР были из категории «контактных», что указывает на вероятность превалирования профессионального фактора в приобретении антител. В учреждениях АПП и СП МР примерно поровну распределились по категориям контакта с больными вирусом, и положительные результаты были выявлены в обоих категориях, что не позволяет в силу ограниченности выборки говорить о вероятности превалирования профессионального или непрофессионального фактора приобретения антител.

Таким образом, результаты по отдельным медицинским организациям показывают, что серопревалентность у MP определяется не только уровнем профессиональных контактов с пациентами SARS-CoV-2. Данные нашего исследования согласуется с результатами анализа распространения SARS-CoV-2 в Российской Федерации, проведённого Роспотребнадзором, Российским научно-исследовательским противочумным институтом «Микроб» и Российской медицинской академией непрерывного профессионального образования, где установлено, что преимущественное 
заражение SARS-CoV-2 происходит в семейных очагах - 42.7\%, при этом не удаётся установить источник инфекции в $18.8 \%$ случаев, что может быть связано с бессимптомными случаями [ 7].

Одним из актуальных компонентов популяционных исследований на различные инфекционные агенты является возможность дифференциации интенсивности персонального и коллективного иммунитета [34]. Предложено оценивать интенсивность иммунного ответа с помощью КП - математической расчётной величины, имеющей прямую зависимость от концентрации антител (иммуноглобулинов). Расчёт КП целесообразно проводить для оценки концентрации иммуноглобулинов в исследуемых образцах, а также при наблюдении в динамике. В предыдущих исследованиях, в частности, при оценке иммунной прослойки к природно-очаговым инфекциям нами предложена градация КП [35] - очень высокий уровень (КП >6) характеризует формирование «сильного» иммунного ответа, средний и высокий уровень КП (>3.0-6..0) характеризует иммунный ответ «средней интенсивности», низкий КП характеризует иммунный ответ «слабой» интенсивности, а также, по видимому, перекрестные реакции с другими представителям $\beta$-коронавирусов человека. В целом по группе MP с серопозитивными результатами отмечается превалирование доли с очень высоким коэффициентом позитивности (49.1\%), что характеризует высокую напряженность иммунного ответа и может свидетельствовать о продолжительной по времени или продолжающейся сенсибилизации от внешних источников вируса (табл. 3). Низкий КП отмечен у 19.2\% МР с положительным результатом на антитела к вирусу. По-видимому, очень высокий и высокий уровни КП, характеризующие формирование выраженного иммунного ответа даже при бессимптомных формах, характеризуют активный инфекционный процесс, который может реализоваться в клиническую манифестацию и требует в дальнейшем проведения динамического серомониторинга. Отмечена корреляция между величиной серопревалентности у MP медицинской организации с долей

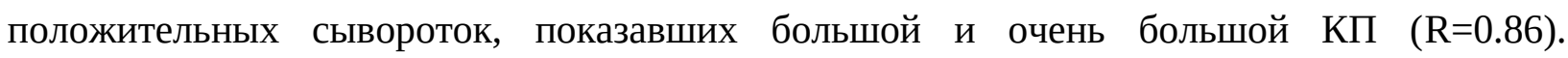
Наибольшая доля сумм проб с большим или очень большим КП наблюдалась в группе медицинских организаций, которые были перепрофилированы для оказания медицинской помощи больным коронавирусной инфекцией и составляла $72.5 \%$, а также у МР СМП (63\%), что свидетельствует о том, что главным источником заражения МР этих медицинских организаций может являться профессиональный контакт. Наименьшая доля проб с большим или очень большим КП наблюдалась в СП (33\%), а также в АПП (0\%) и в двух медицинских организациях, которые были перепрофилированы для оказания медицинской помощи больным коронавирусной инфекцией (MC1 и МС3 - 0\% в обоих), 
где, благодаря эффективным противоэпидемическим мерам, были наименьшие уровни серопревалентности. Полученные данные свидетельствуют о том, что главным источником заражения МР этих организаций могли являться контакты, не связанные с профессиональной деятельностью. Доли проб с большим или очень большим КП в этих четырёх медицинских организациях, имеющих наименьшие значения серопревалентности у МР, достоверно отличались (p<0,001\%) от таковых в остальных шести организациях с большими значениями серопревалентности. Средний и низкий уровень КП возможно характеризуют инаппарантную сероконверсию или перекрестную реактивность с другими вирусами (другим представителям $\beta$-коронавирусов человека) или прочими респираторными вирусами), что требует дальнейших исследований, особенно в аспекте разработки индивидуальных подходов к вакцинации МР.

Таким образом, полученные результаты свидетельствуют о наличии среди МР лиц перенёсших или имеющих бессимптомную форму течения инфекции, вызванную SARS$\mathrm{CoV}-2$, и подтверждают актуальность дальнейшего проведения серологического мониторинга в медицинских организациях различного профиля. Результаты серологического мониторинга могут служить основой для корректирования профилактических мероприятий на базе отдельных медицинских организаций, а с учётом рекомендаций Роспотребнадзора и подбора контингентов для вакцинации к SARS-CoV-2.

\section{Выводы}

1. Серопревалентность по IgG антителам к вирусу SARS-CoV-2 у медицинских работников различных медицинских организаций г. Казани составляет 16.4 \%. Широкое варьирование значения серопревалентности в группах MP различных организаций (3.330.8\%) может свидетельствовать о разном уровне эффективности противоэпидемических мероприятий в данных учреждения и эффективности режима карантина в виде перевода работников на дистанционную форму работы.

2. Среди МР с серопозитивными результатами отмечается превалирование доли с очень высоким КП (49.1\%), что характеризует высокую напряженность иммунного ответа. Отмечена корреляция между величиной серопревалентности у $\mathrm{MP}$ медицинского организаций с долей положительных сывороток с высокими значениями КП.

3. Результаты свидетельствуют о наличии среди МР лиц, перенёсших или имеющих бессимптомную форму течения инфекции, вызванную SARS-CoV-2, что подтверждает актуальность дальнейшего проведения серологического мониторинга в медицинских организациях различного профиля. 
Таблица 1

Table 1

Распределение МР по медицинским организациям

Distribution of MRs by medical organizations

\begin{tabular}{|c|c|c|c|c|c|c|c|c|c|c|}
\hline $\begin{array}{c}\text { Группа } \\
\text { медицинских } \\
\text { организаций } \\
\text { Group of }\end{array}$ & \multicolumn{7}{|c|}{ «высокого риска» } & \multicolumn{2}{|c|}{$\begin{array}{c}\text { «умеренного } \\
\text { риска» } \\
\text { moderate risk }\end{array}$} & $\begin{array}{c}\text { «низкого } \\
\text { риска» } \\
\text { low }\end{array}$ \\
\hline $\begin{array}{c}\text { Условное } \\
\text { обозначение } \\
\text { медицинской } \\
\text { организации } \\
\text { Medical } \\
\text { organization } \\
\text { symbol }\end{array}$ & $\begin{array}{c}\text { MC1 } \\
\text { H1 }\end{array}$ & $\begin{array}{c}\text { MC2 } \\
\text { H2 }\end{array}$ & $\begin{array}{c}\text { MC3 } \\
\text { H3 }\end{array}$ & $\begin{array}{c}\text { MC4 } \\
\text { H4 }\end{array}$ & $\begin{array}{c}\text { MC5 } \\
\text { H5 }\end{array}$ & $\begin{array}{c}\text { MC6 } \\
\text { H6 }\end{array}$ & $\begin{array}{c}\text { MC7 } \\
\text { H7 }\end{array}$ & $\begin{array}{c}\text { СМП } \\
\text { AS }\end{array}$ & $\begin{array}{c}\mathrm{A \Pi} \\
\mathrm{P}\end{array}$ & $\begin{array}{l}\text { CП } \\
\text { SP }\end{array}$ \\
\hline $\begin{array}{c}\text { Кол-во МР } \\
\text { number of } \\
\text { MW }\end{array}$ & 40 & 40 & 30 & 30 & 40 & 39 & 20 & 40 & 20 & 49 \\
\hline
\end{tabular}


Серопревалентность к вирусу SARS-CoV-2 медицинских работников различных учреждений г. Казани.

Seroprevalence to SARS - CoV-2 virus of medical workers of various institutions in Kazan.

\begin{tabular}{|c|c|c|c|c|}
\hline $\begin{array}{c}\text { Обозначение } \\
\text { медицинской } \\
\text { организации } \\
\text { Medical } \\
\text { organization } \\
\text { designation }\end{array}$ & $\begin{array}{c}\text { Количество } \\
\text { обследованных } \\
\text { медицинских } \\
\text { работников } \\
\text { Number of } \\
\text { medical workers } \\
\text { examined }\end{array}$ & $\begin{array}{c}\text { Кол-во } \\
\text { положительных / } \\
\text { доля } \\
\text { Number of } \\
\text { positives / share }\end{array}$ & $\begin{array}{c}\text { Имевших ранее контакт с больными } \\
\text { SARS-CoV-2 / из них положительные на } \\
\text { IgG к SARS-CoV-2 } \\
\text { Previous contact with SARS-CoV-2 } \\
\text { patients / of them positive for IgG to } \\
\text { SARS-CoV-2 }\end{array}$ & $\begin{array}{l}\text { Не имевших ранее контакт с больными } \\
\text { SARS-CoV-2 / из них положительные на } \\
\text { IgG к SARS-CoV-2 } \\
\text { Those who have not had previous contact } \\
\text { with SARS-CoV-2 patients / of them are } \\
\text { positive for IgG to SARS-CoV-2 }\end{array}$ \\
\hline $\begin{array}{c}\text { MC } 1 \\
\text { H1 }\end{array}$ & 40 & $2 / 5 \%$ & $40 / 2$ & $0 / 0$ \\
\hline $\begin{array}{c}\text { MC } 2 \\
\text { H } 2\end{array}$ & 40 & $7 / 17.5 \%$ & $12 / 3$ & $28 / 4$ \\
\hline $\begin{array}{c}\text { MC } 3 \\
\text { H3 }\end{array}$ & 30 & $1 / 3.3 \%$ & $30 / 1$ & $0 / 0$ \\
\hline $\begin{array}{c}\text { MC } 4 \\
\text { H4 }\end{array}$ & 30 & 5 / 16.7\% & $30 / 5$ & $0 / 0$ \\
\hline $\begin{array}{c}\text { MC } 5 \\
\text { H5 }\end{array}$ & 40 & $7 / 17.5 \%$ & $40 / 7$ & $0 / 0$ \\
\hline $\begin{array}{c}\text { MC } 6 \\
\text { H6 }\end{array}$ & 39 & 12 / 30.8\% & $29 / 10$ & $10 / 2$ \\
\hline $\begin{array}{c}\text { MC } 7 \\
\text { H7 }\end{array}$ & 20 & $6 / 30.0$ & $20 / 6$ & $0 / 0$ \\
\hline
\end{tabular}




\begin{tabular}{|c|c|c|c|c|}
\hline $\begin{array}{c}\text { CMП } \\
\text { АS }\end{array}$ & 40 & $11 / 27.5 \%$ & $40 / 11(27,5 \%)$ & $0 / 0(0 \%)$ \\
\hline $\begin{array}{c}\text { АПП } \\
\text { Р }\end{array}$ & 20 & $3 / 15.0 \%$ & $10 / 1(10 \%)$ & $10 / 2(20 \%)$ \\
\hline $\begin{array}{c}\text { СП } \\
\text { SP }\end{array}$ & 49 & $3 / 6.1 \%$ & $20 / 2$ & $29 / 1$ \\
\hline $\begin{array}{c}\text { Группа 1 } \\
\text { Group 1 }\end{array}$ & 239 & $40 / 16.7 \%$ & $50(83,3 \%) / 12(24 \%)$ & $38(95 \%) / 6(15.7 \%)$ \\
\hline $\begin{array}{c}\text { Группа 2 } \\
\text { Group 2 }\end{array}$ & 60 & $14 / 23.3 \%$ & $20(40,8 \%) / 2(10 \%)$ & $29(16,7 \%) / 2(20 \%)$ \\
\hline $\begin{array}{c}\text { Группа 3 } \\
\text { Group 3 }\end{array}$ & 49 & $3 / 6.1 \%$ & $271(77,8 \%) / 48(17,7 \%)$ & $77(22,1 \%) / 9(11,7 \%)$ \\
\hline $\begin{array}{c}\text { Всего } \\
\text { Tоtal }\end{array}$ & 348 & $57 / 16.4 \%$ & $(3.4 \%)$ \\
\hline
\end{tabular}


Структура серопревалентности к вирусу SARS--CoV-2 медиц

The structure of seroprevalence to the SARS virus - CoV-2 of medical workers by the level of positivity ratеинских работников по уровню коэффициента позитивности

\begin{tabular}{|c|c|c|c|c|c|c|}
\hline $\begin{array}{c}\text { Обозначение } \\
\text { медицинской } \\
\text { организации } \\
\text { Medical } \\
\text { organization } \\
\text { designation }\end{array}$ & $\begin{array}{c}\text { Количество } \\
\text { обследованных } \\
\text { медицинских } \\
\text { работников } \\
\text { Number of } \\
\text { medical workers } \\
\text { examined }\end{array}$ & $\begin{array}{c}\text { Кол-во } \\
\text { положительных } \\
\text { Number of } \\
\text { positives }\end{array}$ & $\begin{array}{c}\text { Низкий КП 1.1-2.0 } \\
\text { Low coefficient of } \\
\text { positivity1.1-2.0 }\end{array}$ & $\begin{array}{l}\text { Средний КП >2.0- } \\
3.0 \\
\text { Medium coefficient } \\
\text { of positivity >2.0-3.0 }\end{array}$ & $\begin{array}{c}\text { Высокий КП >3.0- } \\
6.0 \\
\text { Hhigh coefficient } \\
\text { of positivity } \\
>3.0-6.0\end{array}$ & $\begin{array}{c}\text { Очень высокий } \\
\text { КП >6 } \\
\text { Very high } \\
\text { coefficient of } \\
\text { positivity >6 }\end{array}$ \\
\hline $\begin{array}{c}\text { MC } 1 \\
\text { H1 }\end{array}$ & 40 & 2 & - & 2 & - & - \\
\hline $\begin{array}{c}\text { MC } 2 \\
\text { H2 }\end{array}$ & 40 & 7 & - & 2 & 4 & 1 \\
\hline $\begin{array}{c}\text { MC } 3 \\
\text { H3 }\end{array}$ & 30 & 1 & 1 & - & - & - \\
\hline $\begin{array}{c}\text { MC } 4 \\
\text { H4 }\end{array}$ & 30 & 5 & 3 & - & - & 2 \\
\hline $\begin{array}{c}\text { MC } 5 \\
\text { H5 } \\
\end{array}$ & 40 & 7 & 3 & - & 1 & 3 \\
\hline $\begin{array}{c}\text { MC } 6 \\
\text { H6 }\end{array}$ & 39 & 12 & - & - & 1 & 11 \\
\hline MC 7 & 20 & 6 & - & - & 1 & 5 \\
\hline
\end{tabular}




\begin{tabular}{|c|c|c|c|c|c|c|}
\hline H7 & & & & & & \\
\hline $\begin{array}{c}\text { СМП } \\
\text { AS }\end{array}$ & 40 & 11 & 3 & 1 & 2 & 5 \\
\hline $\begin{array}{c}\text { АПП } \\
\text { Р }\end{array}$ & 20 & 3 & 1 & 2 & - & - \\
\hline $\begin{array}{l}\text { CП } \\
\text { SP }\end{array}$ & 49 & 3 & - & 2 & - & 1 \\
\hline $\begin{array}{c}\text { Группа } 1 \\
\text { Group } 1\end{array}$ & 239 & 40 & 7 & 4 & 7 & 22 \\
\hline $\begin{array}{c}\text { Группа } 2 \\
\text { Group } 2\end{array}$ & 60 & 14 & 4 & 3 & 2 & 5 \\
\hline $\begin{array}{c}\text { Группа } 3 \\
\text { Group } 3 \\
\end{array}$ & 49 & 3 & 0 & 2 & 0 & 1 \\
\hline Всего & 348 & $57(16,4 \%)$ & 11 & 9 & 9 & $28(49,1 \%)$ \\
\hline
\end{tabular}

